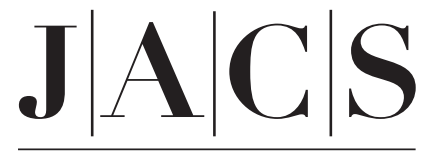

A R T I C L E S

Published on Web 02/12/2008

\title{
Adsorption of a Statherin Peptide Fragment on the Surface of Nanocrystallites of Hydroxyapatite
}

\author{
Peng-Huan Chen, ${ }^{\dagger}$ Yao-Hung Tseng, ${ }^{\dagger}$ Yun Mou, ${ }^{\dagger}$ Yi-Ling Tsai, ${ }^{\dagger}$ Syuan-Ming Guo, ${ }^{\dagger}$ \\ Shing-Jong Huang, ${ }^{\dagger}$ Steve S.-F. Yu, ${ }^{\ddagger}$ and Jerry C. C. Chan ${ }^{\star}, \dagger$ \\ Department of Chemistry, National Taiwan University, No. 1, Section 4, Roosevelt Road, Taipei \\ 106, Taiwan, and Institute of Chemistry, Academia Sinica, Nankang, Taipei 115, Taiwan
}

Received September 1, 2007; E-mail: chanjcc@ntu.edu.tw

\begin{abstract}
Statherin is an active inhibitor of calcium phosphate precipitation in the oral cavity. For many studies of the interaction between statherin and hydroxyapatite (HAp), the samples are prepared by a direct mixing of statherin or its fragment with well-crystalline HAp crystals. In this work, the HAp sample is precipitated in the presence of peptide fragment derived from the $\mathrm{N}$-terminal 15 amino acids of statherin (SN-15). The in situ prepared HAp crystallites are nanosized, leading to a significant increase of the peptide amount adsorbed on the HAp surface. The enhancement in NMR sensitivity allows, for the first time, the measurement of a two-dimensional ${ }^{13} \mathrm{C}-{ }^{13} \mathrm{C}$ correlation spectrum for a ${ }^{13} \mathrm{C}$ uniformly labeled peptide sample adsorbed on mineral surface. The measurement time is about $18.5 \mathrm{~h}$ at a field strength of $7.05 \mathrm{~T}$. Preliminary results suggest that there may exist two different mechanisms for the interaction between SN-15 and HAp. In addition to the one which will cause a conformational change near the N-terminal, $\mathrm{SN}-15$ may also be absorbed on the HAp surface by simple electrostatic interaction, without any significant conformational changes of the peptides.
\end{abstract}

\section{Introduction}

Biomineralization, which is a process describing the formation of composite materials in organisms, ${ }^{1}$ is a particularly challenging research area because it is extremely difficult to study the interaction between two dissimilar organic and inorganic nanophases by diffraction techniques. Thus, it has long been a mystery how living organisms control the mineral deposition with hierarchical structures. Several research groups have attempted to control nucleation and growth of crystals from organic templates by in vitro experiments ${ }^{2-5}$ and in natural biomineralizing systems. ${ }^{6,7}$ These studies suggest that nucleation of the mineral phase occurs on the peptide surfaces which expose repetitive patterns of anionic groups. Consequently, the anionic groups tend to concentrate the inorganic cations followed by nucleation of crystal. Substantial efforts have also been made to investigate the relationship between the morphologies of inorganic crystals and their biopolymer or organic templates. ${ }^{8-16}$

\footnotetext{
National Taiwan University.

$\doteqdot$ Academia Sinica.

(1) Lowenstam, H. A.; Weiner, S. On Biomineralization; Oxford University Press: Oxford, U.K., 1989.

(2) Aizenberg, J.; Black, A. J.; Whitesides, G. M. Nature 1999, 398, 495

(3) Hartgerink, J. D.; Beniash, E.; Stupp, S. I. Science 2001, 294, 1684

(4) Stupp, S. I.; Braun, P. V. Science 1997, 277, 1242.

(5) Whaley, S. R.; English, D. S.; Hu, E. L.; Barbara, P. F.; Belcher, A. M. Nature 2000, 405, 665.

(6) Mann, S. J. Chem. Soc., Dalton Trans. 1997, 3953.

(7) Weiner, S.; Addadi, L. J. Mater. Chem. 1997, 7, 689.

(8) Gonzalez-McQuire, R.; Chane-Ching, J. Y.; Vignaud, E.; Lebugle, A.; Mann, S. J. Mater. Chem. 2004, 14, 2277.

(9) Matsumoto, T.; Okazaki, M.; Inoue, M.; Hamada, Y.; Taira, M.; Takahashi, J. Biomaterials 2002, 23, 2241.

(10) Zhang, H. G.; Zhu, Q. S.; Wang, Y. Chem. Mater. 2005, 17, 5824.

(11) Walsh, D.; Kingston, J. L.; Heywood, B. R.; Mann, S. J. Cryst. Growth $1993,133,1$.
}

On the other hand, our knowledge concerning the structurefunction relationship of the proteins involved in biomineralization processes is very limited. The primary function of these proteins, such as statherin, is to mediate the cellular function at the mineral surface. It is currently accepted that polyacidic regions commonly found in proteins which interact with hydroxyapatite are responsible for adhering the proteins to hydroxyapatite. ${ }^{17}$ However, the molecular mechanism of the interaction between biopolymers and mineral surfaces remains largely unknown because of the lack of structural data with atomistic resolution. For example, it is unclear whether the charged residues near the $\mathrm{N}$-terminus of statherin will recognize the spatial arrangement of the ions on the hydroxyapatite (HAp) surface or the statherin-HAp binding is simply the result of electrostatic interaction.

In the past few years, it has been shown that solid-state NMR (SSNMR) is an effective analytical tool to probe for the polypeptide-surface interaction. ${ }^{18-22}$ These works represent the first successful step in unraveling the mechanism of biominer-

(12) Donners, J.; Nolte, R. J. M.; Sommerdijk, N. Adv. Mater. 2003, 15, 313.

(13) Yan, L.; Li, Y. D.; Deng, Z. X.; Zhuang, J.; Sun, X. M. Int. J. Inorg. Mater. 2001, 3, 633.

(14) Sarda, S.; Heughebaert, M.; Lebugle, A. Chem. Mater. 1999, 11, 2722.

(15) Wang, X.; Zhuang, J.; Peng, Q.; Li, Y. D. Adv. Mater. 2006, 18, 2031.

(16) Cao, M. H.; Wang, Y. H.; Guo, C. X.; Qi, Y. J.; Hu, C. W. Langmuir 2004, 20, 4784

(17) Gorski, J. P. Calcif. Tissue Int. 1992, 50, 391.

(18) Fernandez, V. L.; Reimer, J. A.; Denn, M. M. J. Am. Chem. Soc. 1992 114, 9634 .

(19) Raghunathan, V.; Gibson, J. M.; Goobes, G.; Popham, J. M.; Louie, E. A.; Stayton, P. S.; Drobny, G. P. J. Phys. Chem. B 2006, 110, 9324

(20) Gibson, J. M.; Popham, J. M.; Raghunathan, V.; Stayton, P. S.; Drobny, G. P. J. Am. Chem. Soc. 2006, 128, 5364 .

(21) Gibson, J. M.; Raghunathan, V.; Popham, J. M.; Stayton, P. S.; Drobny, G. P. J. Am. Chem. Soc. 2005, 127, 9350 . 
alization at the molecular level, and a lot of valuable structural information concerning the orientations of the statherin or its $\mathrm{N}$-terminal fragment with respect to the HAp surface has been obtained. ${ }^{23}$ However, experimental high-resolution structural models of the polypeptides adsorbed on the mineral surface are still not available. On the other hand, a significant progress in computational studies of protein structures on solid surfaces has been observed in recent years. ${ }^{24}$ As a result, the resolution of the current experimental structural model of the statherin-HAp system is so low that it can broadly match a group of computationally predicted structures which have a root-meansquare-deviation of $20 \AA .{ }^{25}$ The major difficulty in the aforementioned SSNMR studies is the poor signal sensitivity. With refererence to the protocol of sample preparation documented in these studies, the peptide sample was chemisorbed to HAp by mixing the peptide and the crystalline HAp samples in a buffer solution. The surface area of a commercial HAp sample is in general less than $80 \mathrm{~m}^{2} / \mathrm{g}$. Given that the polypeptideHAp sample packed in a 4-mm rotor (a typical sample holder in SSNMR experiments) is about $40 \mathrm{mg}$ and that the statherin coverage on HAp is about $5.2 \times 10^{-7} \mathrm{~mol} / \mathrm{m}^{2},{ }^{26}$ the amount of peptide amenable to measurement is estimated to be $1.7 \mu \mathrm{mol}$. This limited peptide content renders it difficult to acquire the one-dimensional ${ }^{13} \mathrm{C}$ SSNMR spectra with good signal-to-noise ratio, let alone the two-dimensional ${ }^{13} \mathrm{C}-{ }^{13} \mathrm{C}$ correlation spectra. Without the resolution enhancement offered by two-dimensional NMR techniques, the information content per sample becomes very limited.

In this work, we suggest to prepare the HAp sample in the presence of polypeptides so that the peptide amount adsorbed on the HAp surface can be significantly enhanced. The 15-residue peptide derived from the N-terminal of the salivary protein statherin (SN-15), which also displays functional activities in controlling HAp growth, ${ }^{27}$ was chosen for the in situ sample preparation. A series of physical methods were used to characterize the peptides adsorbed on the HAp surface. In particular, a two-dimensional ${ }^{13} \mathrm{C}-{ }^{13} \mathrm{C}$ correlation spectrum with decent signal-to-noise ratio was measured for the ${ }^{13} \mathrm{C}$ uniformly labeled SN-15 adsorbed on HAp surface. It is anticipated that many other two-dimensional techniques developed for uniformly ${ }^{13} \mathrm{C}$ labeled polypeptides can hence be applied. ${ }^{28}$ It is noteworthy that the protocol of sample preparation we developed is a general one and it is readily applied to the study of other protein-HAp interactions using SSNMR or other physical techniques.

\section{Materials and Methods}

Peptide Synthesis and Characterization. All the chemicals for peptide synthesis were obtained from NovaBiochem unless stated otherwise. SN-15 polypeptides, with the sequence DpSpSEEKFLRRIGRFG, were synthesized on an automated Odyssey microwave peptide synthesizer (CEM Corp.), where pS stands for phosphoserine. Standard

(22) Drobny, G. P.; Long, J. R.; Karlsson, T.; Shaw, W.; Popham, J.; Oyler, N.; Bower, P.; Stringer, J.; Gregory, D.; Mehta, M.; Stayton, P. S. Annu. Rev. Phys. Chem. 2003, 54, 531.

(23) Goobes, G.; Stayton, P. S.; Drobny, G. P. Prog. Nucl. Magn. Reson. Spectrosc. 2007, 50, 71 .

(24) Gray, J. J. Curr. Opin. Struct. Biol. 2004, 14, 110.

(25) Makrodimitris, K.; Masica, D. L.; Kim, E. T.; Gray, J. J. J. Am. Chem. Soc. 2007, 10.1021/ja074602v.

(26) Goobes, R.; Goobes, G.; Campbell, C. T.; Stayton, P. S. Biochemistry 2006, $45,5576$.

(27) Raj, P. A.; Johnsson, M.; Levine, M. J.; Nancollas, G. H. J. Biol. Chem. 1992, 267, 5968.

(28) Baldus, M. Prog. Nucl. Magn. Reson. Spectrosc. 2002, 41, 1. 9-fluorenylmethoxycarbonyl (FMOC) chemistry with preloaded FmocGly-Wang resin (substitution $0.82 \mathrm{mmol} / \mathrm{g}$; Bachem) was used. The solvent was $\mathrm{N}, \mathrm{N}$-dimethylformamide (DMF). The deprotection agent was $20 \%$ piperidine with $0.1 \mathrm{M} N$-hydroxybenzotriazole (HOBt) in DMF, and the activator was $0.5 \mathrm{M}$ 2-(1H-benzotriazole-1-yl)-1,1,3,3tetramethyluronium hexafluorophosphate (HBTU) in DMF. The activator base was $2 \mathrm{M}$ diisopropylethylamine (DIEA) in $N$-methylpyrrolidinone (NMP). The synthesis scale was $0.1 \mathrm{mmol}$, with a 5 -fold excess for each unlabeled amino acid and a 2-fold excess for each labeled amino acid. For the synthesis of the sample SN15KG, where the residues $\mathrm{K} 6$ and $\mathrm{G} 12$ were isotopically labeled, the uniformly ${ }^{13} \mathrm{C}$ - and ${ }^{15} \mathrm{~N}$-labeled amino acids with FMOC protection were obtained from Cambridge Isotope Laboratories. Unless stated otherwise, the deprotection was carried out at $37^{\circ} \mathrm{C}$ for $30 \mathrm{~s}(13 \mathrm{~W}$ microwave irradiation), followed by higher temperature at $75{ }^{\circ} \mathrm{C}$ for $180 \mathrm{~s}(25 \mathrm{~W})$, and the coupling reaction was carried out at $75^{\circ} \mathrm{C}$ for $300 \mathrm{~s}(5 \mathrm{~W})$. For the $\mathrm{R}$ residues, the coupling step was first carried out at room temperature for $30 \mathrm{~min}$ (no microwave irradiation) and then at $75{ }^{\circ} \mathrm{C}$ for $300 \mathrm{~s}(5$ W). For the residues including $\mathrm{D}, \mathrm{pS}$, and the ${ }^{13} \mathrm{C}$ and ${ }^{15} \mathrm{~N}$ uniformly labeled residues, the deprotection and coupling steps were carried out without microwave irradiation. The deprotection times were set to 35 min. The coupling times were set to 2 and $4 \mathrm{~h}$ for $\mathrm{pS}$ and the labeled residues, respectively. The crude peptides were cleaved using standard protocols [reaction for $120 \mathrm{~min}$ in $95 \%$ trifluoroacetic acid (TFA) with $2.5 \%$ triisopropylsilane (TIS), $2.5 \%$ deionized (DI) water] and precipitated in cold tert-butyl methyl ether. Precipitated peptides were washed three times with cold tert-butyl methyl ether and then lyophilized. The peptides were purified by high-performance liquid chromatography at $50{ }^{\circ} \mathrm{C}$, using a water/acetonitrile gradient with $0.1 \%$ TFA and a preparative scale Vydac C18 reverse-phase column. Samples of $10 \mathrm{mg} /$ injection were dissolved in $5 \mathrm{~mL}$ of $5 \%$ acetonitrile and $0.1 \%$ TFA in DI water before being injected onto the column. Fractions containing SN-15 were collected at the concentration of $16 \%$ acetonitrile and were frozen in liquid nitrogen immediately after being collected. Peptide purity was at least $90 \%$ as determined by mass spectrometry.

Adsorption of Peptides onto the HAp Surface. All the chemicals were obtained from Acros and used without purification. The sample SN15HAp was prepared according to the protocol developed by Drobny and co-workers. ${ }^{20,29}$ Briefly, a powder sample of $50 \mathrm{mg}$ of commercial HAp $\left(77 \mathrm{~m}^{2} / \mathrm{g}\right)$ was added to the solution of $20 \mathrm{mg}$ of SN-15 in $5 \mathrm{~mL}$ of phosphate buffer. The $\mathrm{pH}$ was adjusted to 7.4 with $\mathrm{NaOH}$ and $\mathrm{HCl}$. The mixture was incubated in an orbital shaker under $175 \mathrm{rpm}$ at $37^{\circ} \mathrm{C}$ for $4 \mathrm{~h}$. The powder sample collected by centrifuge was washed three times with phosphate buffer and then lyophilized. The sample SN15HAp7.4 was prepared by the following in-situ synthesis. Typically, $0.6 \mathrm{mmol}$ of $\mathrm{Ca}\left(\mathrm{NO}_{3}\right)_{2} \cdot 4 \mathrm{H}_{2} \mathrm{O}$ was dissolved in $15 \mathrm{~mL}$ of DI water, with the $\mathrm{pH}$ adjusted to 7.4. Another solution of $0.54 \mathrm{mmol} \mathrm{K}_{2} \mathrm{HPO}_{4}$. $3 \mathrm{H}_{2} \mathrm{O}$ in $15 \mathrm{~mL}$ of DI water was prepared to which $20 \mathrm{mg}$ of SN-15 (0.01 mmol) was added. The $\mathrm{pH}$ was again adjusted to 7.4. The two solutions were mixed and shaken vigorously for $5 \mathrm{~min}$. The mixture was then aged at $60^{\circ} \mathrm{C}$ for $12 \mathrm{~h}$. The precipitate collected by centrifuge was washed three times with DI water and then lyophilized. For the sample SN15HAp9, the pH of the two precursor solutions were both adjusted to 9.0 before mixing. The mixture was aged at $37^{\circ} \mathrm{C}$ for $4 \mathrm{~h}$ and then collected in a way similar to that for SN15HAp7.4. The sample SN15KG-HAp9 was similarly prepared as the SN15HAp9, except that the residues $\mathrm{K} 6$ and $\mathrm{G} 12$ were ${ }^{13} \mathrm{C}$ uniformly labeled. The control samples HAp7.4 and HAp9 were prepared at pH equal to 7.4 and 9.0, respectively, without adding $\mathrm{SN}-15$. The control sample SN10HAp9 was prepared identically with SN15HAp9, except that the SN-15 peptide was replaced by SN-10 (KFLRRIGRFG), which was derived from SN15 by truncating its $\mathrm{N}$-terminal fragment DpSpSEE.

Characterization. X-ray diffraction (XRD) analysis was performed on a Mac Science 18MPX diffractometer, using $\mathrm{Cu} \mathrm{K} \alpha$ radiation $(\lambda=$

(29) Shaw, W. J.; Long, J. R.; Dindot, J. L.; Campbell, A. A.; Stayton, P. S.; Drobny, G. P. J. Am. Chem. Soc. 2000, 122, 1709. 
$1.5418 \AA$ A). The Brunauer-Emmett-Teller (BET) surface area of the samples were obtained from the $\mathrm{N}_{2}$ adsorption-desorption isotherm measured using a Micrometry Tristar system, where the samples were degassed at $200^{\circ} \mathrm{C}$ under reduced pressure $\left(10^{-3}\right.$ Torr $)$ for $16-20 \mathrm{~h}$ before each measurement. Absorbance Fourier-transform infrared (FTIR) spectra were collected using a Magna-IR 550 spectrometer (series II), in the range of $400-4000 \mathrm{~cm}^{-1}$. Thermal gravimetric analysis (TGA) was performed on a NETZSCH TG209 thermal gravimetric analyzer. Initially, the temperature was increased to $120^{\circ} \mathrm{C}$ using a heating rate of $10^{\circ} \mathrm{C} / \mathrm{min}$. After annealing of the sample at $120^{\circ} \mathrm{C}$ for $30 \mathrm{~min}$, the temperature was increased further to $700{ }^{\circ} \mathrm{C}$ with the same temperature gradient. Circular dichroism (CD) experiments were performed using an Aviv CD 202 spectrometer (AVIV) calibrated with (+)-10-camphorsulfonic acid at $298 \mathrm{~K}$. A cuvette $(2 \mathrm{~mm}$ path length and $300 \mu \mathrm{L}$ in volume) was filled with $\mathrm{SN}-15$ (ca. $100 \mu \mathrm{M}$ ) buffered at different $\mathrm{pH}$ values and temperatures. For the measurements at variable temperatures, the sample solution was equilibrated for $2 \mathrm{~min}$ prior data acquisition. All the $\mathrm{CD}$ spectra were recorded in the range from 190 to $260 \mathrm{~nm}$ at steps of $0.5 \mathrm{~nm}$ and with a bandwidth of $1 \mathrm{~nm}$. Each CD spectrum was an average of three scans.

Solid-State NMR. All NMR experiments were carried out at ${ }^{31} \mathrm{P}$ and ${ }^{1} \mathrm{H}$ frequencies of 121.5 and $300.1 \mathrm{MHz}$, respectively, on a Bruker DSX300 NMR spectrometer equipped with commercial 2.5 and $4 \mathrm{~mm}$ probes. The measurements were carried out at ambient temperature. The sample was confined in the middle of the rotor volume using Teflon spacers. The variation of the magic-angle spinning (MAS) frequency was limited to $\pm 2 \mathrm{~Hz}$ using a commercial pneumatic control unit (Bruker, MAS II). For the spin-counting experiments, the ${ }^{13} \mathrm{C}\left\{{ }^{1} \mathrm{H}\right\}$ crosspolarization MAS (CPMAS) experiments were carried out using the 4 $\mathrm{mm}$ probe at a spinning frequency of $9.5 \mathrm{kHz}$. A field strength of 80 $\mathrm{kHz}$ was set for the two-pulse phase modulated (TPPM) decoupling during the acquisition period.$^{30}$ Recycle delay was set to $3 \mathrm{~s}$.

For the SN15KG-HAp9, the ${ }^{13} \mathrm{C} /{ }^{13} \mathrm{C}$ chemical shift correlation spectra were measured at an MAS frequency of $12 \mathrm{kHz}$ using the $4 \mathrm{~mm}$ probe. The sample mass was $40 \mathrm{mg}$. During the contact time $(1.5 \mathrm{~ms})$, the ${ }^{1} \mathrm{H}$ nutation frequency was set to $50 \mathrm{kHz}$ and that of ${ }^{13} \mathrm{C}$ was linearly ramped through the Hartmann-Hahn matching condition. ${ }^{31}$ The radio frequency-driven recoupling (RFDR) technique was employed to achieve homonuclear polarization transfer. ${ }^{32}$ The $\pi$ pulse $(6.8 \mu \mathrm{s})$ trains were phase cycled according to the XY-16 scheme. ${ }^{33}$ The mixing time was set to $2.67 \mathrm{~ms}$. Proton decoupling was set to $80 \mathrm{kHz}$. Quadrature detection in the $F_{1}$ dimension was achieved by the hypercomplex approach. ${ }^{34}$ For each $t_{1}$ increment 256 transients were accumulated, and a total of 64 increments were done at steps of $50 \mu$ s. Recycle delay was set to $2 \mathrm{~s}$. TPPM decoupling of $80 \mathrm{kHz}$ was set during the $t_{1}$ and $t_{2}$ evolution periods, and the continuous-wave proton decoupling of the same strength was applied during the mixing time. ${ }^{13} \mathrm{C} N M R$ chemical shifts were referenced to tetramethylsilane (TMS), using adamantane as the secondary reference standard. The correlation spectrum of SN15KG was obtained using the $2.5 \mathrm{~mm}$ probe, under a spinning frequency of $25 \mathrm{kHz}$. The sample mass was $5.8 \mathrm{mg}$. Adiabatic ramping was employed during the contact time, ${ }^{35,36}$ used during the mixing time. ${ }^{37}$ For each $t_{1}$ increment 256 transients were accumulated, and a total of 64 increments were done at steps of $40 \mu \mathrm{s}$.

(30) Bennett, A. E.; Rienstra, C. M.; Auger, M.; Lakshmi, K. V.; Griffin, R. G. J. Chem. Phys. 1995, 103, 6951 .

(31) Metz, G.; Wu, X. L.; Smith, S. O. J. Magn. Reson. A 1994, 110, 219.

(32) Bennett, A. E.; Rienstra, C. M.; Griffiths, J. M.; Zhen, W. G.; Lansbury, P. T.; Griffin, R. G. J. Chem. Phys. 1998, 108, 9463.

(33) Gullion, T.; Baker, D. B.; Conradi, M. S. J. Magn. Reson 1990, 89, 479.

(34) Ernst, R. R.; Bodenhausen, G.; Wokaun, A. Principles of Nuclear Magnetic Resonance in One and Two Dimensions; Clarendon Press: Oxford, U.K., 1987.

(35) Hediger, S.; Meier, B. H.; Kurur, N. D.; Bodenhausen, G.; Ernst, R. R. Chem. Phys. Lett. 1994, 223, 283.

(36) Hediger, S.; Meier, B. H.; Ernst, R. R. Chem. Phys. Lett. 1995, 240, 449.

(37) Ishii, Y. J. Chem. Phys. 2001, 114, 8473.

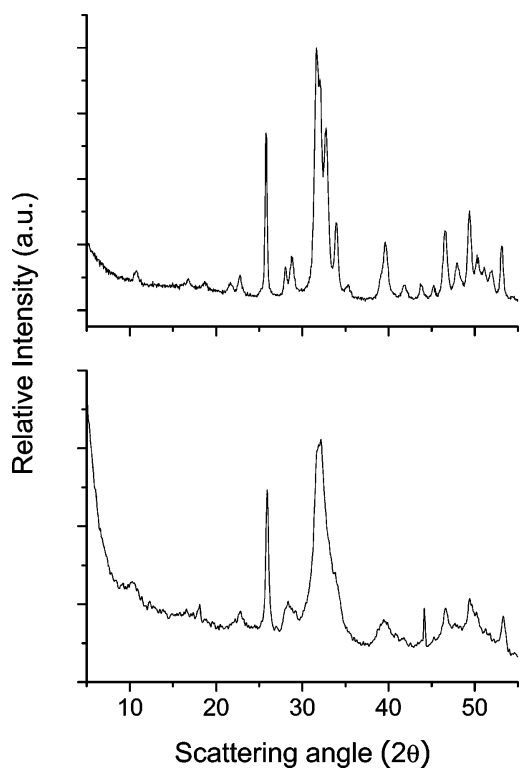

Figure 1. XRD patterns measured for the SN15HAp9 (lower trace) and the commercial HAp samples (upper trace).

\section{Results and Discussion}

XRD and BET Surface Areas. The XRD patterns of SN15HAp9 and commercial HAp sample were measured and are shown in Figure 1. The reflection at $2 \theta=10.8^{\circ}$ is the characteristic peak of HAp (Joint Committee for Powder Diffraction Studies, JCPDS, 24-0033). The pattern of SN15HAp9 resembles closely to that measured for a commercial HAp sample (the top trace). The XRD patterns obtained for SN15HAp7.4 and the control samples are nearly identical with that observed for SN15HAp9 (data not shown), and the poor resolution of their diffraction patterns is attributed to the small size and/or strains of the crystallites. ${ }^{38}$ A similar XRD pattern has also been reported for nanocrystalline HAp. ${ }^{39}$ On the basis of the Scherrer formula, ${ }^{40}$ the size of the diffraction domain calculated from the peak at $2 \theta=25.9^{\circ}$ is found to be $23.3 \pm$ 0.3 and $16.0 \pm 0.1 \mathrm{~nm}$ for HAp9 and SN15HAp9, respectively. Comparable data were obtained for other samples. The nanosize of the crystallites has also been confirmed in the scanning electron microscopy images of the samples (Supporting Information). Consistent with the XRD results, the BET surface area of HAp (Acros), HAp7.4, and HAp9 were determined to be 77,125 , and $208 \mathrm{~m}^{2} / \mathrm{g}$, respectively.

Peptide Amount on the HAp Surface. The samples of SN15HAp7.4 and SN15HAp9 were prepared under the conditions of high temperature and high $\mathrm{pH}$, respectively. It is therefore necessary to examine whether SN15 will be denatured under these nonphysiological conditions. With reference to the CD spectra shown in Figure 2, the conformation of SN-15 at $\mathrm{pH} 9$ is very similar to that at $\mathrm{pH}$ 7.2. At elevated temperature, the helical content of SN-15 is somewhat diminished but the basic features of the conformation are largely maintained. Additional measurements show that the conformations of $\mathrm{SN}$ 15 in DI water and in phosphate buffer at $\mathrm{pH} 7.2$ are nearly the

(38) Klug, H. P.; Alexander, L. E. X-ray diffraction procedures of polycrystalline and amorphous materials; John Wiley \& Sons: New York, 1974.

(39) Jäger, C.; Welzel, T.; Meyer-Zaika, W.; Epple, M. Magn. Reson. Chem. 2006, 44, 573.

(40) Vieira, A.; Hancock, R.; Limeback, H.; Schwartz, M.; Grynpas, M. J. Dent. Res. 2003, 82, 909. 

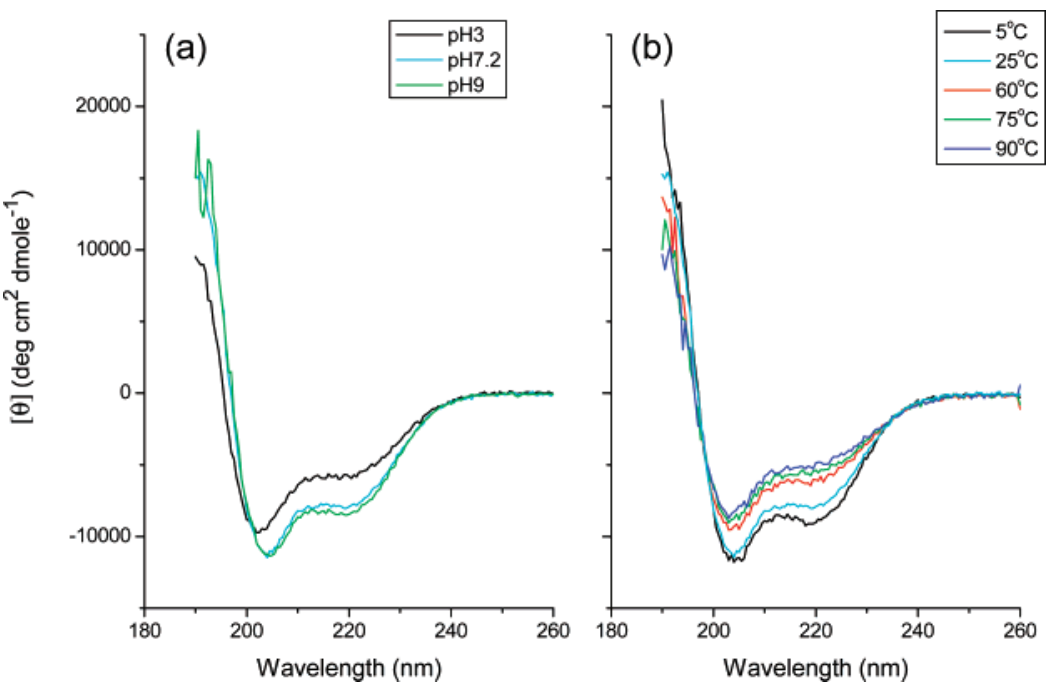

Figure 2. $\mathrm{CD}$ spectra of $\mathrm{SN}-15$ measured at different conditions: (a) different $\mathrm{pH}$ values at $25^{\circ} \mathrm{C}$; (b) different temperatures at $\mathrm{pH} 7.2$.

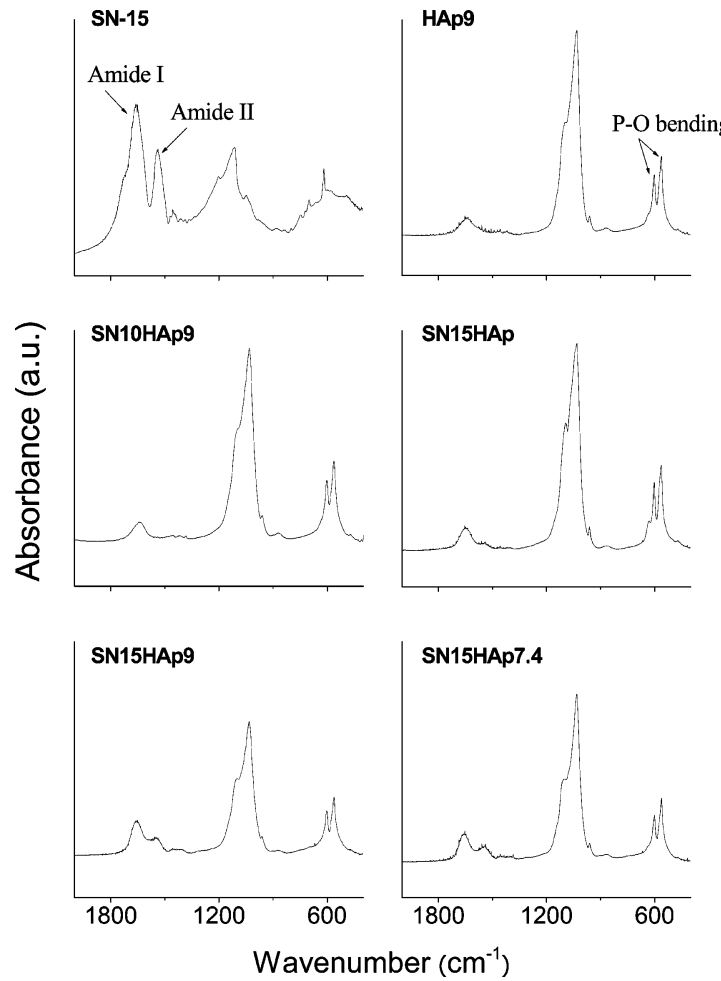

Figure 3. FT-IR spectra measured for different samples.

same (data not shown). Therefore, the samples SN15HAp7.4 and SN15HAp9 are suitable model compounds for the study of the interaction between statherin and HAp. To prove the case that SN15HAp7.4 and SN15HAp9 have larger amounts of SN15 than the SN15HAp sample, we have carried out FT-IR, TGA, and ${ }^{13} \mathrm{C}\left\{{ }^{1} \mathrm{H}\right\}$ CPMAS measurements for our samples. With reference to the FT-IR spectra shown in Figure 3, strong $\mathrm{P}-\mathrm{O}$ bending absorptions occur at 562 and $601 \mathrm{~cm}^{-1} .41,42$ The SN15 sample has the characteristic peaks at 1657 and $1540 \mathrm{~cm}^{-1}$, which are assigned to the amide-I and amide-II bands, respectively. ${ }^{8}$ Because the amide-I band overlaps with the bending mode of $\mathrm{H}_{2} \mathrm{O}$ at $1630 \mathrm{~cm}^{-1}$, we take the intensity ratio of the

(41) Takadama, H.; Kim, H. M.; Kokubo, T.; Nakamura, T. Chem. Mater. 2001, 13,1108 .

(42) Lin, K. S. K.; Tseng, Y. H.; Mou, Y.; Hsu, Y. C.; Yang, C. M.; Chan, J. C. C. Chem. Mater. 2005, 17, 4493.

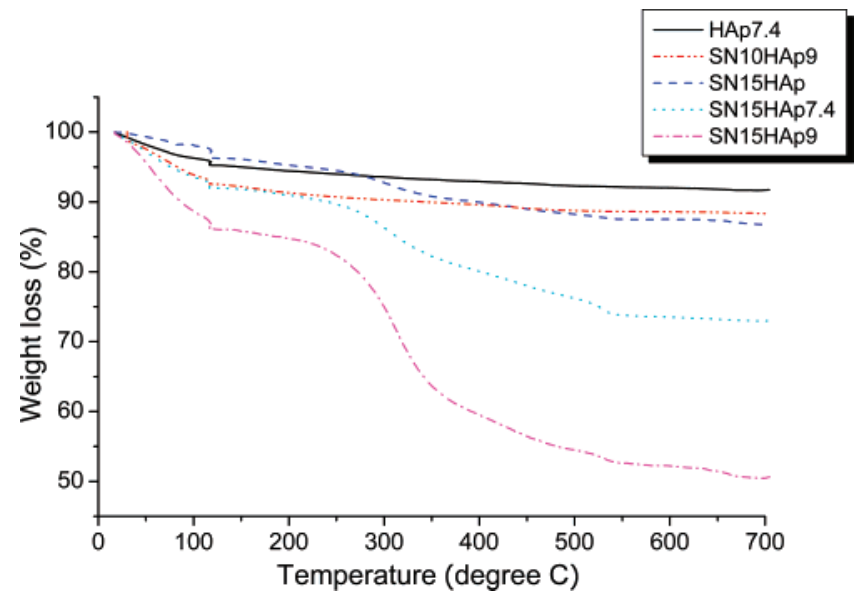

Figure 4. TGA results obtained for different samples.

amide-II to the $\mathrm{P}-\mathrm{O}$ bending $\left(565 \mathrm{~cm}^{-1}\right)$ modes as the spectral marker to determine the relative amount of peptide adsorbed on HAp surface. ${ }^{8}$ The ratios were determined to be $0.09 \pm 0.03$, $0.22 \pm 0.01$, and $0.29 \pm 0.02$ for SN15HAp, SN15HAp7.4, and SN15HAp9, respectively. The ratio determined for each sample does not directly reveal the amount of peptides, but we can compare the ratios of different samples to infer the extent of the increase in the peptide amount. We observe that the amide-II absorptions of SN15HAp9 and SN15HAp7.4 are more intensive than that of SN15HAp, showing a higher peptide content of the former two samples. This observation is consistent with the BET data, where the surface area of HAp9 is found to be 1.7 times larger than that of HAp7.4, which in turn is larger than HAp (Acros) by a factor of 1.6. For the control sample SN10HAp9, there should be relatively little peptide chemisorbed onto the HAp surface because the peptide SN10 does not contain any negatively charged residues. Accordingly, no significant amide-II adsorption is observed for SN10HAp9, which proves that our washing procedure can remove any peptides not chemisorbed on the HAp surface. The TGA results shown in Figure 4 indicate that the control samples HAp7.4 and SN10HAp9 do not contain any organic species, whereas the weight losses in the thermal region from 200 to $600{ }^{\circ} \mathrm{C}$ for SN15HAp, SN15HAp7.4, and SN15HAp9 reveal their peptide amounts of $7.8 \pm 0.1,14.1 \pm 0.2$, and $29.1 \pm 0.3 \mathrm{wt} \%$, respectively. The 


\section{$\mathrm{SN}-15$}

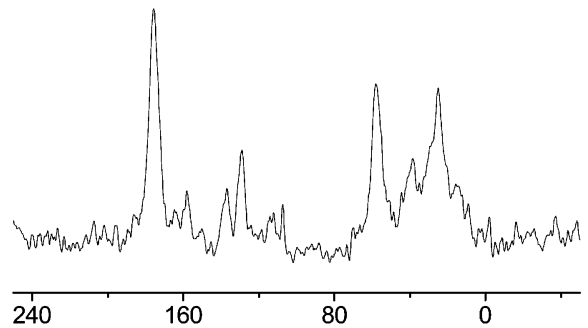

SN15HAp7.4

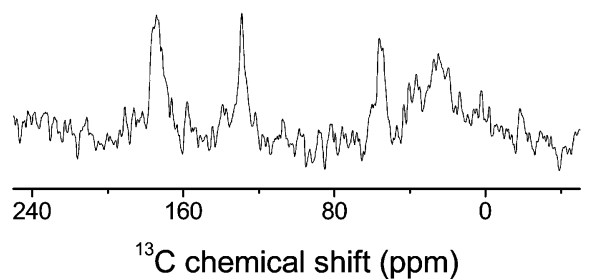

SN15HAp9

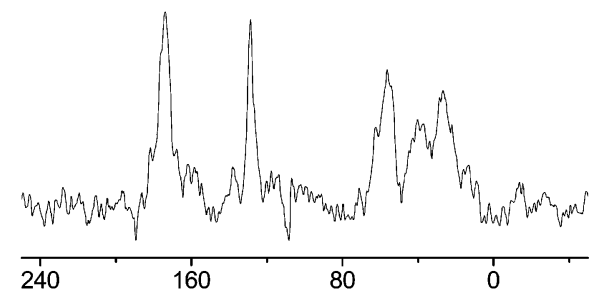

SN15HAp

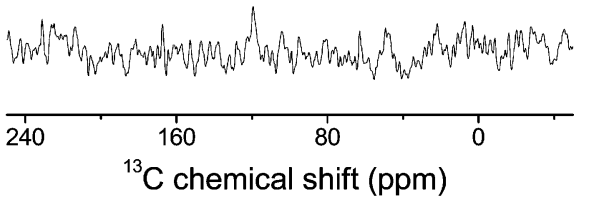

Figure 5. ${ }^{13} \mathrm{C}\left\{{ }^{1} \mathrm{H}\right\}$ CPMAS spectra measured for different natural-abundance samples at a spinning frequency of $9.5 \mathrm{kHz}$. All the samples are of natural abundance. The sample mass and the number of scan were set to (15.3 mg, 15360), (35.8 mg, 25600), (36.4 mg, 20480), and (40.5 mg, 25600$)$ for SN-15, SN15HAp, SN15HAp7.4, and SN15HAp9, respectively. The peptide amount in the SN15HAp9 sample is estimated to be $4.3 \mu$ mol and the corresponding $S / N$ ratio in the carbonyl region is about 10 . The measurement time for the SN15HAp9 sample was $21.3 \mathrm{~h}$.

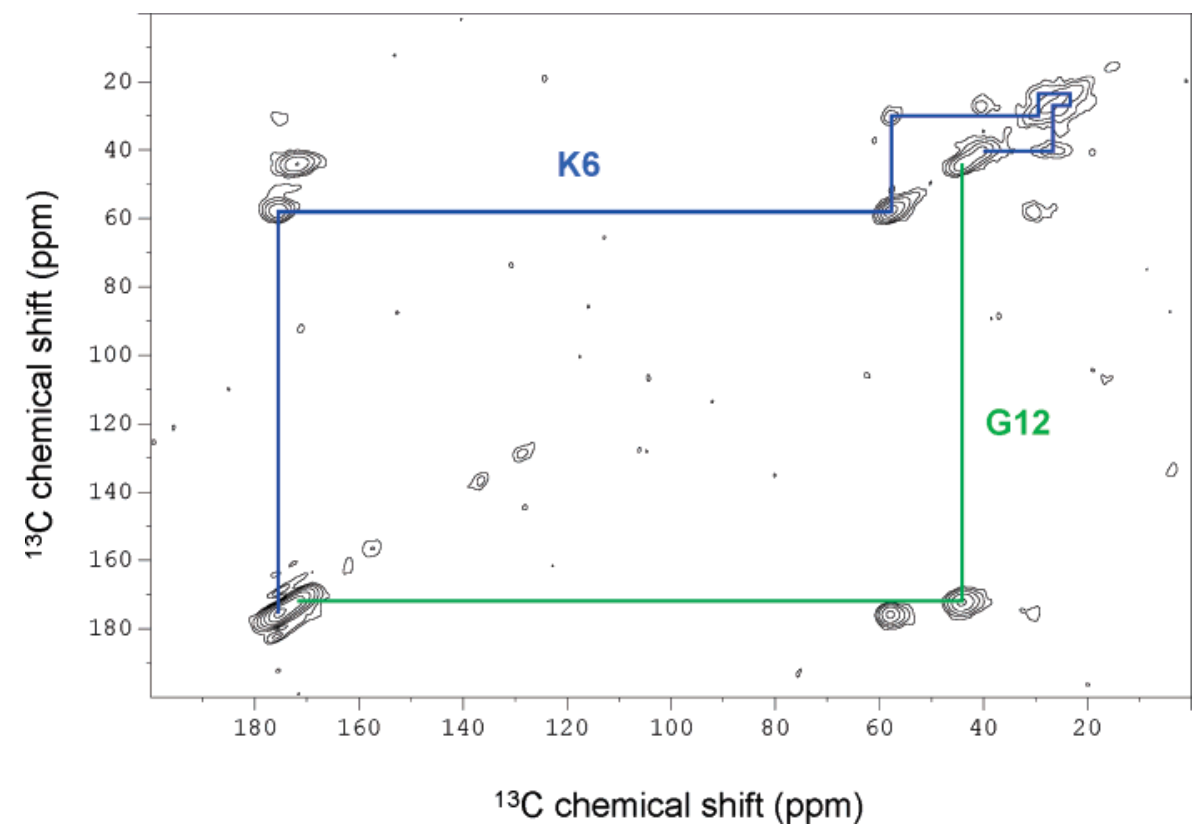

Figure 6. ${ }^{13} \mathrm{C}-{ }^{13} \mathrm{C}$ correlation spectrum measured for the SN15KG sample. The cross-peaks of the residues K6 and G12 are assigned sequentially.

data have been corrected for the weight losses of the control samples. The TGA result obtained for pure SN15 is shown in the Supporting Information. Compared with the FTIR data, the peptide amount of the SN15HAp9 sample inferred from the TGA result is overestimated, which can be attributed to the significant amount of water not removed by lyophilization. A similar phenomenon was observed in our study of glutaric acidHAp system, ${ }^{43}$ which is rationalized by the water molecules trapped between the peptides and the HAp surface. As an

(43) Tseng, Y. H.; Mou, Y.; Chen, P. H.; Tsai, T. W. T.; Hsieh, C. I.; Mou, C. Y.; Chan, J. C. C. Magn. Reson. Chem. 2008, in press. independent verification, we measured the ${ }^{13} \mathrm{C}\left\{{ }^{1} \mathrm{H}\right\}$ CPMAS spectra for our natural abundance samples (Figure 5). All the spectra were measured under the same experimental condition except for the number of scans. Although CPMAS experiments in general do not warrant quantitative analysis, the $\mathrm{CP}$ dynamics of the carbonyl signals $(165-180 \mathrm{ppm})$ are expected to be approximately the same for the SN-15 in free form and in bound state. The sample $\mathrm{SN}-15$ was taken as the spin-counting standard. After normalization of the signal integrals in the carbonyl region by the sample mass and the number of scans, the peptide amounts of SN15HAp7.4 and SN15HAp9 were 


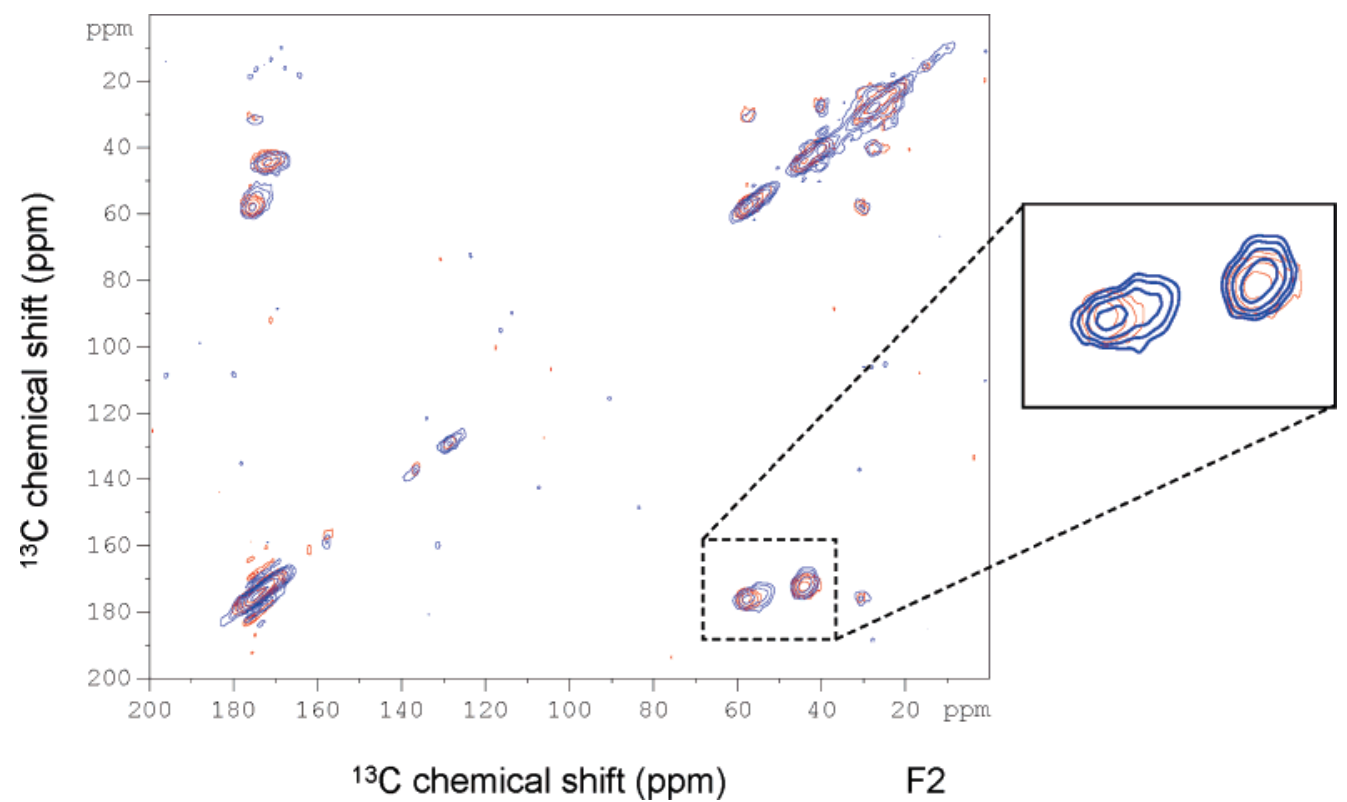

Figure 7. Overlay ${ }^{13} \mathrm{C}-{ }^{13} \mathrm{C}$ correlation spectrum of SN15KG (red) and SN15KG-HAp9 (blue). The inset highlights the $\mathrm{C}_{\alpha}-\mathrm{C}^{\prime}$ cross-peaks of K6 and G12. The measurement time for the SN15KG-HAp9 sample was $18.5 \mathrm{~h}$.

Table 1. ${ }^{13} \mathrm{C}$ NMR Chemical Shift $(\delta, \mathrm{ppm})$ and Line Width Data $\left(\Delta v_{1 / 2}, \mathrm{ppm}\right)$ for SN-15 and SN15KG-HAp9a

\begin{tabular}{|c|c|c|c|c|c|c|c|c|}
\hline \multirow[b]{3}{*}{ atom } & \multirow[b]{3}{*}{ param } & \multicolumn{2}{|c|}{ SN-15 } & \multicolumn{3}{|c|}{ SN15KG-HAp9 } & \multicolumn{2}{|c|}{ random coilb } \\
\hline & & \multirow[b]{2}{*}{ K6 } & \multirow[b]{2}{*}{ G12 } & \multicolumn{2}{|c|}{ K6 } & \multirow[b]{2}{*}{ G12 } & \multirow[b]{2}{*}{ K } & \multirow[b]{2}{*}{ G } \\
\hline & & & & major & minor & & & \\
\hline \multirow[t]{2}{*}{$\mathrm{C}^{\prime}$} & $\delta$ & 175.6 & $172.1 / 172.6^{c}$ & 175.6 & 174.1 & $171.5 / 171.9^{c}$ & 174.9 & 173.2 \\
\hline & $\Delta \nu_{1 / 2}$ & 3.3 & 4.5 & 3.2 & 4.3 & 5.4 & & \\
\hline \multirow[t]{2}{*}{$\mathrm{C}_{\alpha}$} & $\delta$ & 57.9 & 44.2 & 57.3 & 54.5 & 44.0 & 54.5 & 43.4 \\
\hline & $\Delta v_{1 / 2}$ & 3.0 & 4.0 & 3.4 & 4.2 & 3.7 & & \\
\hline \multirow[t]{2}{*}{$\mathrm{C}_{\beta}$} & $\delta$ & 30.2 & & 30.2 & 32.4 & & 31.4 & \\
\hline & $\Delta v_{1 / 2}$ & 3.5 & & 3.0 & 3.8 & & & \\
\hline \multirow[t]{2}{*}{$\mathrm{C}_{\delta}$} & $\delta$ & 27.3 & & 27.4 & & & 27.3 & \\
\hline & $\Delta v_{1 / 2}$ & 3.9 & & 2.4 & & & & \\
\hline \multirow[t]{2}{*}{$\mathrm{C}_{\kappa}$} & $\delta$ & 40.1 & & 39.8 & & & 40.2 & \\
\hline & $\Delta v_{1 / 2}$ & 3.0 & & 2.7 & & & & \\
\hline
\end{tabular}

${ }^{a}$ The data corresponding to the $\mathrm{C}_{\gamma}$ of $\mathrm{K} 6$ cannot be characterized due to resolution limitation. Data analysis was performed on the spectrum with number of scans equal to 1024 (Supporting information), resulting in a total measurement time of $74 \mathrm{~h} .{ }^{b}$ Random-coil shifts taken from Wishart et al. ${ }^{46}$ and adjusted to the TMS reference. ${ }^{c}$ Data reported by Shaw et al. ${ }^{48}$

found to be $14.8 \pm 0.6$ and $21.4 \pm 0.5 \mathrm{wt} \%$, respectively. The signal-to-noise ratio for the SN15HAp spectrum is not good enough for spectral analysis. As expected, no ${ }^{13} \mathrm{C}\left\{{ }^{1} \mathrm{H}\right\}$ CPMAS signal is observed for the spectrum measured for SN10HAp9 (data not shown). With reference to Figure 5, it is interesting to find that the signals of the phenyl rings in the region of 120 ppm are significantly higher for the SN-15 in bound state than in free form. Such enhancement in the CP dynamics for SN-15 in bound state is due to the damping of the flipping motion of the phenyl rings, as pointed out by Drobny and co-workers. ${ }^{20}$ In principle, the use of a larger rotor $(7 \mathrm{~mm})$ may further increase the peptide amount but the lower spinning frequency will complicate the study of uniformly ${ }^{13} \mathrm{C}$ labeled samples.

Under our preparation conditions, the concentration of SN15 required to totally suppress the HAp precipitation is about $2.7 \mathrm{mM},{ }^{44}$ whereas the concentration of $\mathrm{SN}-15$ we added to the reaction mixture is $0.33 \mathrm{mM}$ only. Therefore, HAp precipitation would occur and the $\mathrm{SN}-15$ peptides anchoring on the HAp surface were obtained after washing. On the basis

(44) Schwartz, S. S.; Hay, D. I.; Schluckebier, S. K. Calcif. Tissue Int. 1992, 50,511 . of our BET, TGA, FTIR, and NMR data, the peptide loading on the HAp surface is presumably the same for SN15HAp, SN15HAp7.4, and SN15HAp9. The highest peptide amount found in SN15HAp9 is attributed to its highest HAp surface area. Because SN-15 can significantly slow down the crystal growth but not the nucleation process of HAp, ${ }^{45}$ HAp precipitation in the presence of $\mathrm{SN}-15$ will lead to a considerable enhancement of the surface area.

SN-15 in the Bound State. Figure 6 shows the ${ }^{13} \mathrm{C}-{ }^{13} \mathrm{C}$ correlation spectrum measured for the SN15KG sample. The cross-peaks of the residues K6 and G12 were assigned sequentially, and their ${ }^{13} \mathrm{C}$ chemical shifts are summarized in Table 1. The data for K6 are consistent with the finding that $\mathrm{SN}-15$ in free form adopts a helical conformation. ${ }^{27}$ With reference to the spectrum of SN15KG-HAp9 (blue) shown in Figure 7, the chemical shifts of G12 do not have any appreciable changes. On the other hand, there are two sets of cross-peaks observed for K6. The $\mathrm{C}_{\alpha}$ chemical shift of the major component (66\%) bears a close resemblance to that observed for $\mathrm{SN}-15$ in free

(45) Long, J. R.; Shaw, W. J.; Stayton, P. S.; Drobny, G. P. Biochemistry 2001, 40, 15451 . 
form, whereas the minor component $(34 \%)$ has the chemical shift very close to the random coil value. ${ }^{46}$ In fact, the line width data of the minor components are in the range from 3.8 to 4.3 ppm, which is typically found for the random aggregates of polypeptides. ${ }^{47}$ The $2 \mathrm{D}$ NMR measurement was repeated after rehydration of the SN15KG-HAp9 sample. The resulting spectrum confirms that the observed structural heterogeneity is not due to lyophilization (Supporting Information). A possible rationalization is that there are two types of SN15-HAp interacting mechanisms. The mechanism corresponding to the minor component requires the peptide to undergo a conformational change at K6 from a helical to random-coil structure, whereas the conformation near the region of G12 does not have any major changes. This mechanism is consistent with the data reported by Drobny et al., ${ }^{23}$ where it has been demonstrated that the residue G12 has very little interaction with the HAp surface $^{48}$ and that the residue K6 is in close proximity to the HAp surface. ${ }^{21}$ On the other hand, the mechanism corresponding to the major peak component is presumably due to a simple electrostatic interaction between the peptide and the mineral surface so that no significant alternation of the backbone conformation is induced on the polypeptide. This structural scenario is not inconceivable because the surface of the in-situ prepared HAp nanocrystallites are expected to be very irregular. The presence of two binding mechanisms is also supported by the thermodynamic studies of statherin adsorption onto HAp,

(46) Wishart, D. S.; Bigam, C. G.; Holm, A.; Hodges, R. S.; Sykes, B. D. J. Biomol. NMR 1995, 5, 67.

(47) Petkova, A. T.; Ishii, Y.; Balbach, J. J.; Antzutkin, O. N.; Leapman, R. D.; Delaglio, F.; Tycko, R. Proc. Natl. Acad. Sci. U.S.A. 2002, 99, 16742.

(48) Shaw, W. J.; Long, J. R.; Campbell, A. A.; Stayton, P. S.; Drobny, G. P. J. Am. Chem. Soc. 2000, 122, 7118. in which it is concluded that there are two different binding sites for the statherin-HAp interaction. ${ }^{26,49}$ Nevertheless, additional measurements of the chemical shifts of other residues are required to corroborate our data interpretation. In any case, our control experiment on the sample SN10HAp9 suggests that the presence of two adsorption mechanisms is not an artifact due to incomplete washing. At the present stage, it is difficult to discern which mechanism is more biologically relevant and more works are required to refine both mechanisms at the atomic level. To summarize, our major result is that the protocol of sample preparation described in this work can significantly enhance the amount of SN-15 adsorbed on the HAp surface, from typically $2 \mu \mathrm{mols}^{45}$ to $10.8 \mu$ mols per $100 \mathrm{mg}$ of peptideHAp sample. Consequently, many powerful two-dimensional NMR techniques developed for the study of uniformly labeled polypeptides can be applied to facilitate the site-specific determination of the conformation of the peptide absorbed on mineral surface.

Acknowledgment. This work was supported by grants from the National Science Council and the Ministry of Education. We thank the insightful comments of the anonymous reviewers.

Supporting Information Available: SEM images of the samples of SN15HAp, SN15HAp7.4, and SN15HAp9, the TGA results of pure $\mathrm{SN}-15$, and an overlay ${ }^{13} \mathrm{C}-{ }^{13} \mathrm{C}$ correlation spectrum of SN15KG-HAp9 in lyophilized and rehydrated forms. This material is available free of charge via the Internet at http://pubs.acs.org.

\section{JA076607Y}

(49) Goobes, R.; Goobes, G.; Shaw, W. J.; Drobny, G. P.; Campbell, C. T.; Stayton, P. S. Biochemistry 2007, 46, 4725. 